\title{
Novel Multi Tone- SPWM Technique (MT-SPWM) Using Reference Window and Frequency Optimization
}

\author{
Mohammed S. M. A. Khesbak and Ibraheem M. Khaleel \\ Computer Communications Engineering Dept. AL- Rafidain University College, Baghdad - Iraq
}

\begin{abstract}
Due to the vitality of the SPWM technique in industry of the power conversion devices, this paper suggests a new harmonic distortion minimization technique so far called multitone SPWM. This proposed technique aims to inject the modulating waveform with a high frequency component at the low voltage regions (edges of the waveform) to increase number of switching pulses at these regions and hence increase power content of the fundamental component of the output spectrum based on a power redistribution concept. Optimization process was accomplished on the technique key parameters and a considerable of a $21 \%$ reduction was achieved in THD\% compared with the traditional unipolar SPWM technique.
\end{abstract}

Keywords-component; PWM; Inverter; DC to AC; harmonic reduction; power conversion

\section{INTRODUCTION}

In most industrial DC-to-AC applications such as inverters and uninterruptable power supplies, the traditional natural Sinusoidal Pulse Width Modulation SPWM is the main technique involved in such power conversion used in wide range of industrial application where power switching converter are employed [1,2]. Figure 1 shows a typical power circuit diagram used for producing a PWM output waveform from a DC source of power. The circuit named as a full bridge inverter and is used for producing both the Bipolar and Unipolar types of SPWM.

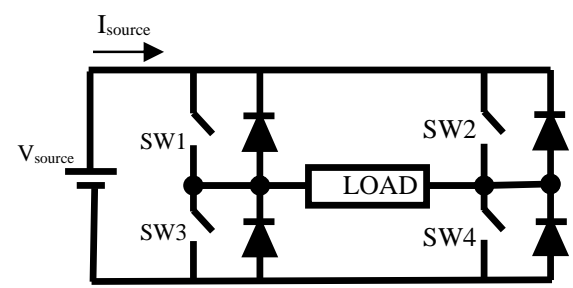

FIGURE I. FULL BRIDGE INVERTER CIRCUIT

The circuit is also called H-Bridge as the load is forming $(\mathrm{H})$ letter together with the four switches. Feedback diodes are provided with each switch and DC sources is applied as the main voltage source to the $\mathrm{H}$-Bridge. Positive output voltage may be obtained by switching ON SW1 and SW4 while a negative output voltage is obtained by turning ON SW2 and SW3.
The popularity of using PWM might be summarized in the following listed features [3, 4].

Due to nature of switching and the fact that switches have reduced switching time and hence reducing power losses.

PWM generation considered easy to generate practically either by analogue or digital circuits.

On the other hand, PWM generation is desired to own the following privileges [5, 6, and 7].

Good utilization of DC power source.

Linear output voltage control.

Low switching losses.

Low amplitudes for the low frequency harmonics compared with the fundamental component leading to reduced total harmonic distortion.

\section{BIPOLAR AND UNIPOLAR SPWM GENERATION}

The generation of a Bipolar SPWM may be explained regarding Figure 2, where two waveforms are used for the process. The first one with lower frequency is called the modulating or reference waveform Vref (sinusoidal waveform) and the second one with much higher frequency is called the carrier Vcr (triangular) waveform. The comparison of the two waveforms will result in either positive or negative DC voltage output and for that reason the process is called Bipolar [8].

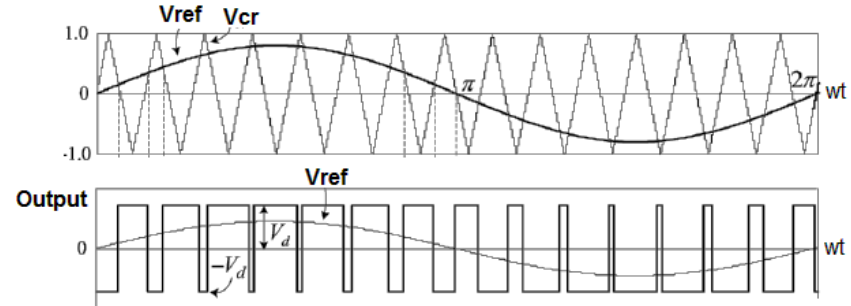

FIGURE II. BIPOL AR SPWM GENERATION WAVEFORMS

Moreover, the generation of the Unipolar SPWM normally requires two sinusoidal (reference) waveforms with same magnitude and frequency but with 180 degree out of phase relation. These two reference waveforms are to be compared with one carrier (triangular) waveform resulting in output of either zero or positive DC voltage and hence the term bipolar rises. Figure 3 shows the unipolar waveform relations and output generation. As a comparison the Unipolar SPWM offers reduced switching losses and generate less EMI [9]. 


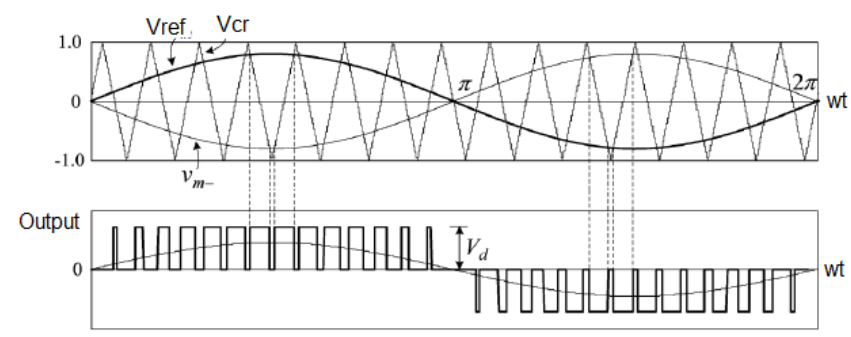

FIGURE III. UNIPOLAR SPWM GENERATION WAVEFORMS

\section{Proposed MT-SPWM TEChNIQUE}

The new SPWM technique proposed in this paper suggests that the modulating (reference) waveform is no longer of one tone frequency. This reference waveform will be composed of two components of sinusoidal frequencies represented by the low frequency (basic frequency) and high frequency (frequency modulated of basic frequency). Figure 4 shows one case of the proposed MT-SPWM technique and how it is possible to generate SPWM with multi-tone modulating reference waveform. The desired frequency of the output waveform was set as $\mathrm{f}=50 \mathrm{~Hz}$ (may be set to $60 \mathrm{~Hz}$ as well) which represent the basic reference frequency of waveform (Vref2). The value of output period time is denoted as (T) and it is the reciprocal value of the desired frequency (f).

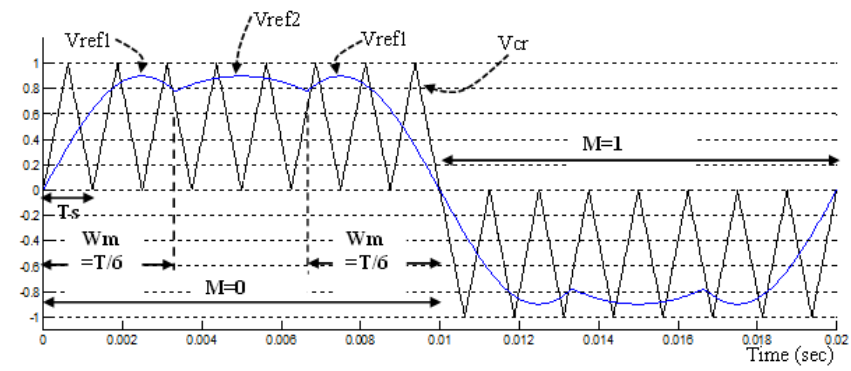

FIGURE IV. UNIPOLAR PROPOSED MT-SPWM GENERATION WAVEFORMS FOR $\mathrm{K}=2$

Moreover defining the new effective parameter (Wm) as the high frequency time window where the Frequency multiplication takes place at the reference waveform converting the basic reference waveform from Vref2 to Vref1 of higher frequency. The relation between these two reference waveforms Vref1 and Vref2 is that Vref 2 has a higher frequency than Vref2 and as follows:

$$
V_{r e f} 1(t)=V_{1} \operatorname{Sin}(2 \pi k f t)
$$

and

$$
V_{\text {ref } 2}(t)=V_{2} \operatorname{Sin}(2 \pi f t)
$$

where V1 and V2 are amplitudes of Vref1(t) and Vref2(t) respectively and $(\mathrm{k})$ is the frequency multiplier factor. These two reference waveforms represent together the reference waveform of the new technique SPWM where $(\mathrm{k})$ and $(\mathrm{Wm})$ are the performance effective key parameters. The aim from such modification in modulating reference waveform from single to multi-tone is to increase the power of the fundamental component at the low frequency edges of the waveform.

\section{MATHEMATICAL MODELLING}

In order to perform an optimization process on the performance key parameters of the new multi-tone proposed technique, it is necessary to represent the waveforms depicted in Figure 4 using a mathematical equations and as follows:

The carrier (triangular) waveform shown in Figure 4 may be derived and described by the following equation;

$$
V 1=(-1)^{M} *\left\{\begin{array}{lr}
\frac{2 t}{T_{s}}-2(N-1) & (N-1) T_{S} \leq t<(N) \frac{T_{S}}{2} \\
\frac{-2 t}{T_{s}}+2 N & (N-1) \frac{T_{S}}{2} \leq t<N T_{S}
\end{array}\right.
$$

where (Ts) is the triangular waveform Period and $(\mathrm{N})$ is the number of triangular cycles within the period $\mathrm{T}$ and it may be represented as;

$$
N=1,2,3, \ldots .,\left(\frac{T}{T_{S}}\right)
$$

Furthermore, $(\mathrm{M})$ is a segmentation indicator for the half cycle of the basic waveform and may be represented as;

$$
M= \begin{cases}0 & 0 \leq t<\frac{T}{2} \\ 1 & \frac{T}{2} \leq t \leq T\end{cases}
$$

Also the modulating (reference) waveform may also be derived using a segmentation method to reflect the effect of frequency multiplication factor $(\mathrm{k})$ and the high frequency time window $(\mathrm{Wm})$ to be as follows;

$$
\text { Vref }=(-1)^{M} * a b s\left\{\begin{array}{lr}
V_{1} \sin (2 \pi f k t) & 0 \leq t<\left(W_{m}+\frac{M T}{2}\right) \\
V_{2} \sin (2 \pi f t) & \left(W_{m}+\frac{M T}{2}\right) \leq t<\left(\frac{T}{2}-W_{m}+\frac{M T}{2}\right) \\
V_{1} \sin (2 \pi f k t) & \left(\frac{T}{2}-W_{m}+\frac{M T}{2}\right) \leq t<\left(\frac{T}{2}+\frac{M T}{2}\right)
\end{array}\right.
$$

Finally and according to the two formulas depicted by (3) and (4), a comparison process may results in producing the required output PWM waveform as;

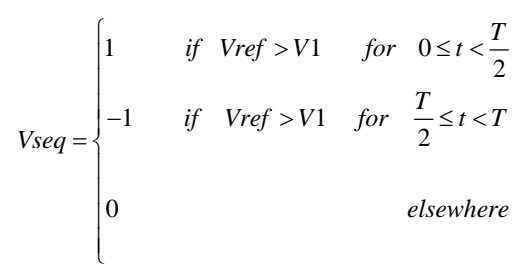




\section{MT-SPWM KEY PARAMETERS OPTIMIZATION}

The optimization process here aims to find the optimum values for the four key parameters involved in the proposed technique (V1, V2, $\mathrm{k}$, and $\mathrm{Wm}$ ) that should results in a minimum percentage Total Harmonic Distortion THD\% of the frequency spectrum of the unfiltered output waveform. The definition of the well-known THD\% criterion is as follows;

$$
\text { THD } \%=\sqrt{\frac{\sum_{\mathrm{n}=2}^{\infty} C_{n}^{2}}{C_{1}^{2}}} \times 100
$$

where $\left(C_{n}\right)$ is the nth harmonic component and $\left(C_{1}\right)$ is the first harmonic frequency component (fundamental) in the frequency spectrum. Although the evaluation of the standard IEEE THD\% depends on the application type, it is still an issue to decide which harmonic criterion to use. However a more general evaluation equation will be considered in this paper represented by (6) and measurement results is evaluated under the IEEE recommended Practice and Requirements for harmonic control in electric power systems [10,11].

Initially V1 and V2 will be set to unity and a MATLAB program was written for optimizing the common effect of both $\mathrm{k}$ and $\mathrm{Wm}$ on the THD\%. Figure 5 shows a 3-dimensional graph reflecting the effect of changing $\mathrm{k}$ from value of 1 to 3 in a 0.1 step of change, and changing Wm from (T/10) to (T/2) with $\mathrm{T}=20 \mathrm{msec}$ in a decreasing step of change.

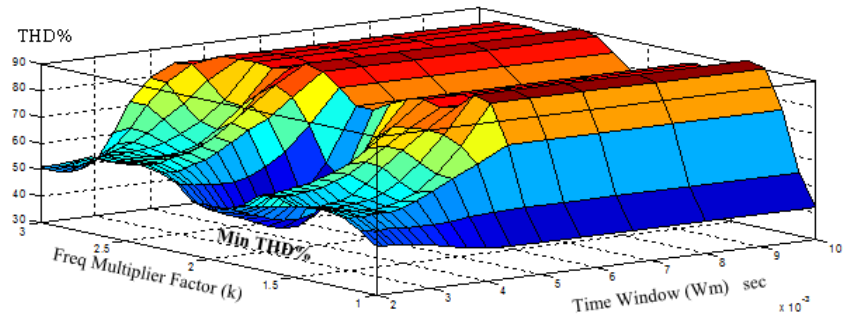

FIGURE V. THREE DIMENSIONAL GRAPH SHOWING THE EFFECT OF CHANGING $\mathrm{W}_{\mathrm{m}}$ AND K ON THD\%

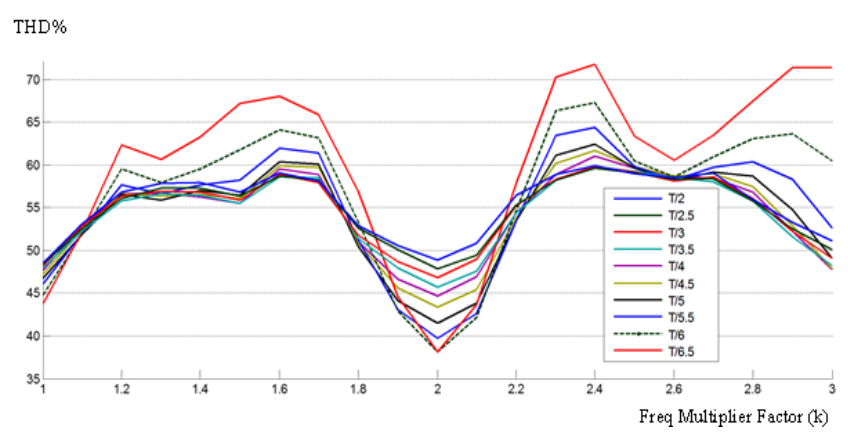

FIGURE VI. TWO DIMENSIONAL GRAPH SHOWING THE EFFECT OF CHANGING $\mathrm{W}_{\mathrm{m}}$ AND K ON THD\%

Moreover, Figure 6 shows a more clear view of the region where a minimum THD\% is occurring through a two dimensional graph where it can be deduced from both graphs together with the results obtained from the optimizing written program that the minimum THD\% may be obtained by tuning $\mathrm{k}$ to value of (2) and using a high frequency time window (Wm) equal to one sixth of desired basic reference period (T/6). Globally, such parameters tuning as resulted by the optimization process will result in a considerable minimization in THD\% of the unfiltered output waveform from $48.5 \%$ of the traditional unipolar SPWM to $38 \%$ for the proposed new MT-SPWM technique. Although the amplitudes V1 and V2 of the multi-tone reference waveform have been involved in the optimization process, it has been found that these parameters have a minor ffect on THD\%.

\section{MT-Spwm Power RE-Distribution EFFECT}

After new approach parameters were optimized for minimum THD\%, it is worth to demonstrate the power redistribution effect of the technique on the frequency spectrum of the unfiltered output waveform. Fourier's coefficients were calculated for the unfiltered output waveform with normalized unity amplitudes and 400 harmonic components were taken in consideration to show a wider spectrum. Figure 7 shows a comparison of two frequency spectrum figures for both the traditional and the MT-SPWM techniques with carrier frequency of $4 \mathrm{kHz}$ and a $50 \mathrm{~Hz}$ desired output frequency.
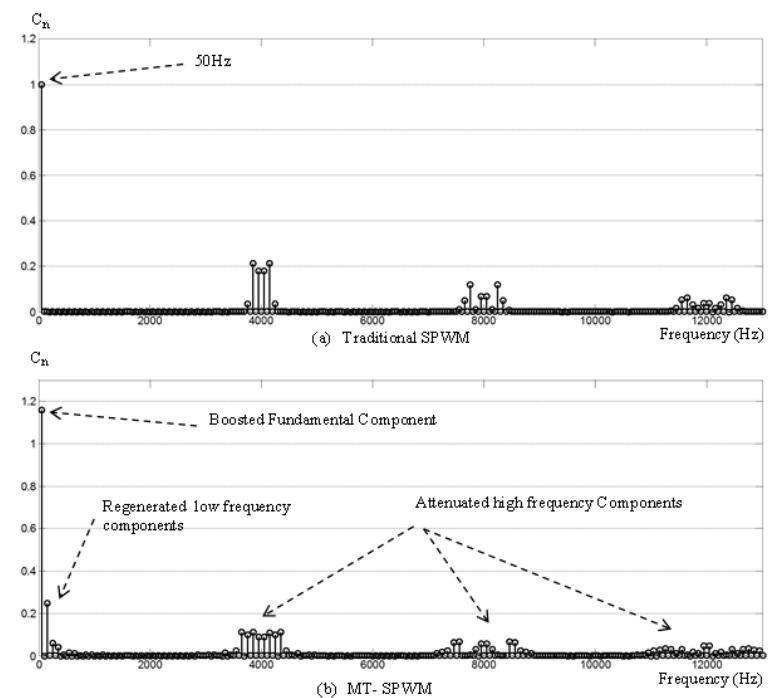

FIGURE VII. FREQUENCY SPECTRUM OF THE UNFILTERED OUTPUT WAVEFORM

The application of the new technique managed to redistribute power from the high frequency switching components to the low frequency components resulting in a boosted fundamental component. However, such power redistribution process also results in the appearance of a very low frequency component which, regardless of having small attenuation, it still considered as a consequence of such process.

\section{CONCLUSIONS}

The new technique proposed is a trend to reduce the harmonic distortion of the frequency spectrum of the wellknown SPWM technique. Applying the multi-tone SPWM new technique requires no additional hardware and only the modulating waveform generation part will be modified as a 
control strategy as it was explained in this paper. This makes the new technique feasible and easy to apply which as per the analysis and simulation results took over in this paper, will offer about $21 \%$ reduction in THD\% compared to the traditional SPWM. Such reduction will occur by setting specific values for the frequency factor and the time window of the high frequency segment of the modulating signal as it was revealed by the optimization process carried out in this paper.

\section{REFERENCES}

[1] Hua Zeqiang, Han Xiaoqing,"Bi-directional DC-DC converter based on the improved PWM modulation," China Science Paper, 2013, Volume 8Issue 7, p.p. 683-687.

[2] Wang Xiaoyan, Liu Jianping,” Error amplifier for PWM controller,” International Conference on Electrical and Control Engineering (ICECE), 2011 Yichang: IEEE, p.p. 2213-2214.

[3] C.S.Sharma, Tali Nagwani, "Simulation and Analysis of PWM Inverter Fed Induction Motor Drive," International Journal of Science, Engineering and Technology Research (IJSETR), Volume 2, Issue 2, February 2013.

[4] Nazmul Islam Raju et al.,” Sinusoidal PWM Signal Generation Technique for Three Phase Voltage Source Inverter with Analog Circuit \& Simulation of PWM Inverter for Standalone Load \& Micro-grid System,” International Journal Of Renewable Energy Research, Volume 3, No.3.

[5] Fangjian Huang, "Analysis of inverter circuit of Sinusoidal Pulse Width Modulation with keystone waveform," 4th National Conference on Electrical, Electronics and Computer Engineering (NCEECE 2015).

[6] Subburam Ramkumar et al.,” A Novel Amplitude Modulated Triangular Carrier Gain Linearization Technique for SPWM Inverter," Serbian Journal Of Electrical Engineering Volume 6, No. 2, November 2009, p.p. 239-252.

[7] P.Manimekalai et al.," H-Bridge Inverter with Sinusoidal Pulse Width Modulation Technique using Unipolar switching for PV applications," International Journal of Applied Engineering Research Volume 10, Number 13 (2015), p.p. 11480-11484.

[8] Kalpesh R. Chaudhary, M J. Mod2, "Switching Control Of Inverter Using SPWM Technique,” International Journal Of Innovative Research In Technology IJIRT, Volume 1, Issue 12 (2015), p.p. 1117-1124.

[9] L. Bowtell and A. Ahfock, "Comparison Between Unipolar And Bipolar Single Phase Grid-Connected Inverters For Pv Applications,” Power Engineering Conference, AUPEC 2007.. Australasian Universities.

[10] IEEE Power and Energy Society, "IEEE Recommended Practice and Requirements for Harmonic Control in Electric Power Systems,” IEEE Std 519 ${ }^{\mathrm{TM}}-2014$ (Revision of IEEE Std 519-1992).

[11] Halpin, “Revisions to IEEE Standard 519-1992”, Transmission and Distribution Conference and Exhibition, 2005/2006 IEEE PES 